Article

\title{
Does Previous Experience of Floods Stimulate the Adoption of Coping Strategies? Evidence from Cross Sectional Surveys in Nigeria and Tanzania
}

\section{Sheila A. Boamah ${ }^{1, \dagger}$, Frederick Ato Armah ${ }^{2, \dagger, *}$, Vincent Z. Kuuire ${ }^{2, \dagger}$, Idowu Ajibade ${ }^{3, \dagger}$, Isaac Luginaah ${ }^{4}$ and Gordon McBean ${ }^{4}$}

1 Arthur Labatt Family School of Nursing, Health Sciences Addition, University of Western Ontario, ON N6A 5C1, Canada; E-Mail: sboamah@uwo.ca

2 Environmental Health and Hazards Lab, Department of Geography, University of Western Ontario, ON N6A 5C2, Canada; E-Mail: zkuuire@uwo.ca

3 Balsillie School of International Affairs, University of Waterloo, Waterloo N2L 6C2, Canada; E-Mail: jajibade@balsillieschool.ca

4 Department of Geography, University of Western Ontario, ON N6A 5C2, Canada; E-Mails: iluginaa@uwo.ca (I.L.); gmcbean@uwo.ca (G.M.)

$\dagger$ These authors contributed equally to this work.

* Author to whom correspondence should be addressed; E-Mail: farmah@uwo.ca; Tel.: +1-519-661-2111 (ext. 82817).

Academic Editor: Yu-Pin Lin

Received: 12 June 2015 / Accepted: 9 November 2015 / Published: 20 November 2015

\begin{abstract}
In sub-Saharan Africa, hydro-meteorological related disasters, such as floods, account for the majority of the total number of natural disasters. Over the past century, floods have affected 38 million people, claimed several lives and caused substantial economic losses in the region. The goal of this paper is to examine how personality disposition, social network, and socio-demographic factors mitigate the complex relationship between stressful life experiences of floods and ocean surges and the adoption of coping strategies among coastal communities in Nigeria and Tanzania. Generalized linear models (GLM) were fitted to cross-sectional survey data on 1003 and 1253 individuals in three contiguous coastal areas in Nigeria and Tanzania, respectively. Marked differences in the type of coping strategies were observed across the two countries. In Tanzania, the zero-order relationships between adoption of coping strategies and age, employment and income disappeared at the multivariate
\end{abstract}


level. Only experience of floods in the past year and social network resources were significant predictors of participants' adoption of coping strategies, unlike in Nigeria, where a plethora of factors such as experience of ocean surges in the past one year, personality disposition, age, education, experience of flood in the past one year, ethnicity, income, housing quality and employment status were still statistically significant at the multivariate level. Our findings suggest that influence of previous experience on adoption of coping strategies is spatially ubiquitous. Consequently, context-specific policies aimed at encouraging the adoption of flood-related coping strategies in vulnerable locations should be designed based on local needs and orientation.

Keywords: flood; coping; environment; perception; experience; coastal; Nigeria; Tanzania

\section{Introduction}

At the global level, hydro-meteorological events are responsible for most disasters [1]. These events, among others, include floods, tropical cyclones, and storm surges. In this study, we focus on floods because they affect more people globally than any other type of natural disaster and cause some of the largest economic, social and humanitarian losses [2]. Anthropogenic climate change is expected to aggravate this dire situation [3,4]. Floods vary greatly in scale and impact, velocity of flow, area covered, content, speed of onset, duration, seasonality and population vulnerability [5-7]. Floods affect over half a billion people every year worldwide, a number that might increase to two billion by 2050 [4]. According to [8], an estimated 2.8 billion individuals were affected by flood events between 1980 and 2009, including approximately 4.6 million rendered homeless. Notwithstanding the enormity of the loss experienced during this period, the figures cited likely substantially underestimate the true impact of climate-induced floods on human population - as estimates of the total affected population and the homeless population were reported in only $64.3 \%$ and $14.9 \%$ of events, respectively [8]. During the last half century until 2002, hydro-meteorological related disasters accounted for almost three-fifth of the total number of natural disasters that occurred in sub-Saharan Africa [9]. Floods alone, accounted for $27 \%$ of these disasters [10]. About 654 floods have affected 38 million people and have claimed almost 13,000 lives in Sub-Saharan Africa alone, and have caused damage estimated at about US \$4 billion [11]. In recent years, the duration and area size of floods have been increasing consistently. The fifth assessment report of the Intergovernmental Panel on Climate Change anticipates that climate change could potentially exacerbate the foregoing impacts of floods across the globe. In this context, coastal cities in Africa are part of the most-at-risk regions of the world [12-15].

According to [16], sub-Saharan Africa has a large and growing coastal population, including a number of important coastal cities. As the coastal cities of Africa expand, many of their residents are pushed to the edges of available land space and some into the most dangerous zones for climate-related hazards. Human-induced climate change is anticipated to intensify flood risks through more frequent heavy precipitation, increased catchment wetness and sea-level rise [3,17-19]. According to [16], a $1 \mathrm{~m}$ of sea-level rise by 2100 , assuming no human response, could inundate at least $18,000 \mathrm{~km}^{2}$ of land and 3.2 million people would be at risk from flooding in Africa. In coastal cities in sub-Saharan Africa, it is the urban poor who are 
usually most at risk of flooding since they reside in slum/informal settlements [20]. In fact, much of the growth in many of sub-Saharan Africa's fastest-growing cities is a result of the expansion of informal settlements on marginal lands, which offer its residents limited access to basic infrastructure. These marginal lands tend to be in flood plains or in tidal basins which may flood twice a day at or near high tides. With sea-level rise and increased storminess, flooding and inundation of coastal areas are expected to generate problems for infrastructure, transportation, agriculture and water resources within the coastal zone [20].

At least two reasons account for our choice of coastal Nigeria and coastal Tanzania for analysis in this study. In many ways, the two coastal areas are quite similar. First, coastal areas in Nigeria (especially Lagos) and Tanzania (especially Dar es Salaam) are regarded as hotspots for both flash and coastal floods. According to the 2012 UN Office for the Coordination for Humanitarian Affairs report, 23 out of 36 states in Nigeria were affected by flooding in 2012, displacing 2.1 million people, killing 363, destroying almost 600,000 houses and creating "unprecedented" ecological damage. In the following year, heavy rains and floods affected about 82,000 people across Nigeria leading to the displacement of 8000 people and damaged more than 6500 homes [21]. Not only have the magnitude of floods intensified in Nigeria, but also the frequency and duration have increased, thus making it very difficult for affected coastal areas to fully recover. Climatic factors such as rising sea-levels are certainly a concern going forward, however for contemporary flooding in Lagos, non-climatic factors such as lack of good urban governance is far more important as a cause of so many people and businesses being at risk of contemporary flooding [22]. Similar trends have been observed in Tanzania as well by the UN Office for the Coordination for Humanitarian Affairs. Between 2010 and 2014, severe floods occurred in Tanzania and the total number of people affected by these floods was over 50,000 (approximately 10,000 families) among which about 10,000 people (approximately 2000 families) were displaced in December 2011. In addition, in April 2014, the death toll in flood events in all the districts of Dar es Salaam was about 20 and an estimated 20,000 people were affected. Despite these losses, coastal issues in general, and flood-related impacts, in particular, are poorly understood for Africa at a sub-continental scale. In particular, the adoption of coping strategies based on previous experience of floods or storm surges (hereafter stressful life experiences), are still ill-understood in the 320 coastal cities (with more than 100,000 people) and nearly 56 million people (2005 estimate) living in low elevation $(<10 \mathrm{~m})$ coastal zones of sub-Saharan Africa [16].

Secondly, the population densities in the coastal areas of the two countries are very high. About $25 \%$ of the population in both Nigeria and Tanzania live in the coastal zone; an area prone to various types of flooding owing to heavy rains, broken dams, and river overflow. Lagos, the former capital of Nigeria and one of the most populous cities in the world, has not escaped the physical, social and economic strains of flooding [23,24]. Its burgeoning population of 15 million people continues to grow rapidly [16,25], expanding into low-lying areas stretching from Badagry Creek to Eti-Osa. Much of the land in and around Lagos is less than two metres above sea level rise; hence, any increase in the intensity of rain and storm surges will likely result in flooding and associated destructive impacts on humans, businesses and infrastructure. In the same way, Dar es Salaam and the islands of Zanzibar in Tanzania have the highest population densities that are threatened by climate change and potential sea-level rise.

It has been argued that previous experience of unpleasant event (e.g., flood) influences behaviour (e.g., decision-making on adoption of coping strategies) [26,27]. Other researchers point out that the decisions we make are rather based on our memories, not our experiences [28,29]. This distinction 
between experience and memory is especially important because personality disposition, social network resources and socio-demographic factors may cumulatively influence the decision of individuals who have previously experienced a stressful life event to adopt coping strategies or not. The aim of this paper is to assess how personality disposition, social network resources and socio-demographic factors attenuate the complex relationship between stressful life experiences in coastal areas and the adoption of flood-related coping strategies. Although, social network resources are broad and complex, in the context of this paper, unless otherwise stated, social network refers explicitly to family ties or family support. In both countries, familial ties are quite strong and serve as the first line of support for coping in the event of disaster.

\section{The Transactional Model of Stress and Coping}

\subsection{Theoretical Framework}

Much research has been conducted on the factors that influence how individuals respond to natural disaster, such as the nature or magnitude of disaster and the capability to cope. In the literature, there are many different styles of coping that people adopt in stressful situations, and some may prove more effective than others, depending on the nature of the event and resources available for the person who is employing them. Studies have shown that people respond to disasters differently and even cultural variations from one country to another may alter ways of understanding and responding to disaster [30,31]. Several theoretical approaches have been used to examine whether and how individuals in society respond to hydrological and climate hazards such as floods. In practice, response to flood impacts may occur on at least two levels: that is whether to adopt coping strategies or not and if so, the specific type of coping strategies to adopt. This paper focuses on the first level of response.

Research indicates that people use both problem-solving and emotional focused coping strategies in effort to alleviate stressful circumstances or events [32]. The predominance of one type of strategy over another is determined, in part, by personal styles and the nature of stressful event; for example, people typically employ problem-focused coping to deal with potential controllable problems such as work-related problems, whereas stressors perceived as less controllable, such as certain kinds of health problems, prompt more emotion-focused approach. In this study, we adopt the Lazarus and Folkman transactional theory of stress and coping [26] to examine how residents in coastal regions in Nigeria and Tanzania respond to floods and factors affecting their decision to adopt coping strategies or not in climate extreme events.

Theories and frameworks from multiple perspectives, such as transactional theory of coping [26] have been explored as a framework for understanding human behaviour in many context and disciplines, such as clinical psychology, nursing and medicine to examine links between stress and other health behaviours. However, in disaster research, its use appears to be limited. The transactional stress-coping theory provides a framework for the identification of stressful events, personal and situational factors that influence such perceptions, related behavioural and emotional responses. Within the transactional model, coping behaviours are considered as ongoing transactions among people and the environmental factors and available resources the person possesses to respond to them [26,33]. This interactive model of stress and coping is applicable to flood research as it offers clear guidelines for exploring antecedents and consequences of stressor appraisals and coping activities in the immediate aftermath of floods. Consistent with the transactional stress-coping theory [26], the proposed framework in this study relies on 
three major concepts: environmental (contextual) demands, individual disposition (appraisal) and response factors (outcomes) (see Figure 1).

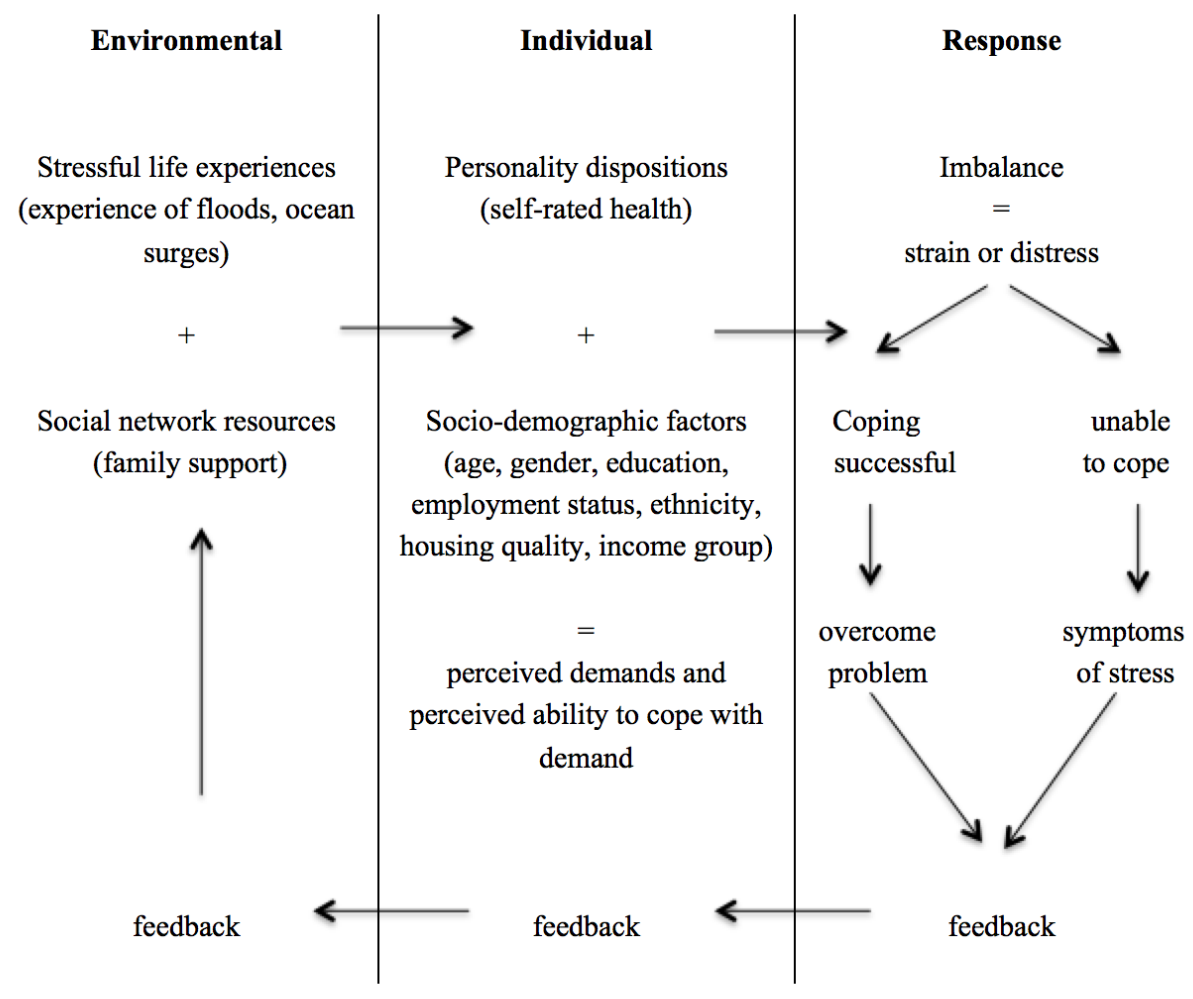

Figure 1. An interactive model of stress appraisal and response adapted from [26].

There are a number of important factors that influences the response to disaster outcomes, as shown in Figure 1. The relationship between an individual and his or her environment and the response to stressful life conditions is complex and non-linear. The nature of the relationship between the person and the environment is considered to be constantly changing - a dynamic/feedback process. The relational nature of coping in this model implies that it is situation and context-specific, as it is shaped by the meaning of the transaction. Coping has three important characteristics: first, coping occurs in response to specific condition in the environment such as disaster (i.e., experience of floods and ocean surge, in the context of this paper). Second, coping is contextual - it is influenced by both the demands of the situation and available resources as influenced by various personal and situational variables (i.e., health status, housing quality). Third, coping is effort-oriented, which refers to behavioural and emotional attempts to manage stressors - the response.

\section{Methods}

\subsection{Study Area}

The study was carried out in coastal communities in West Africa (Nigeria) and East Africa (Tanzania) as shown in Figure 2. 


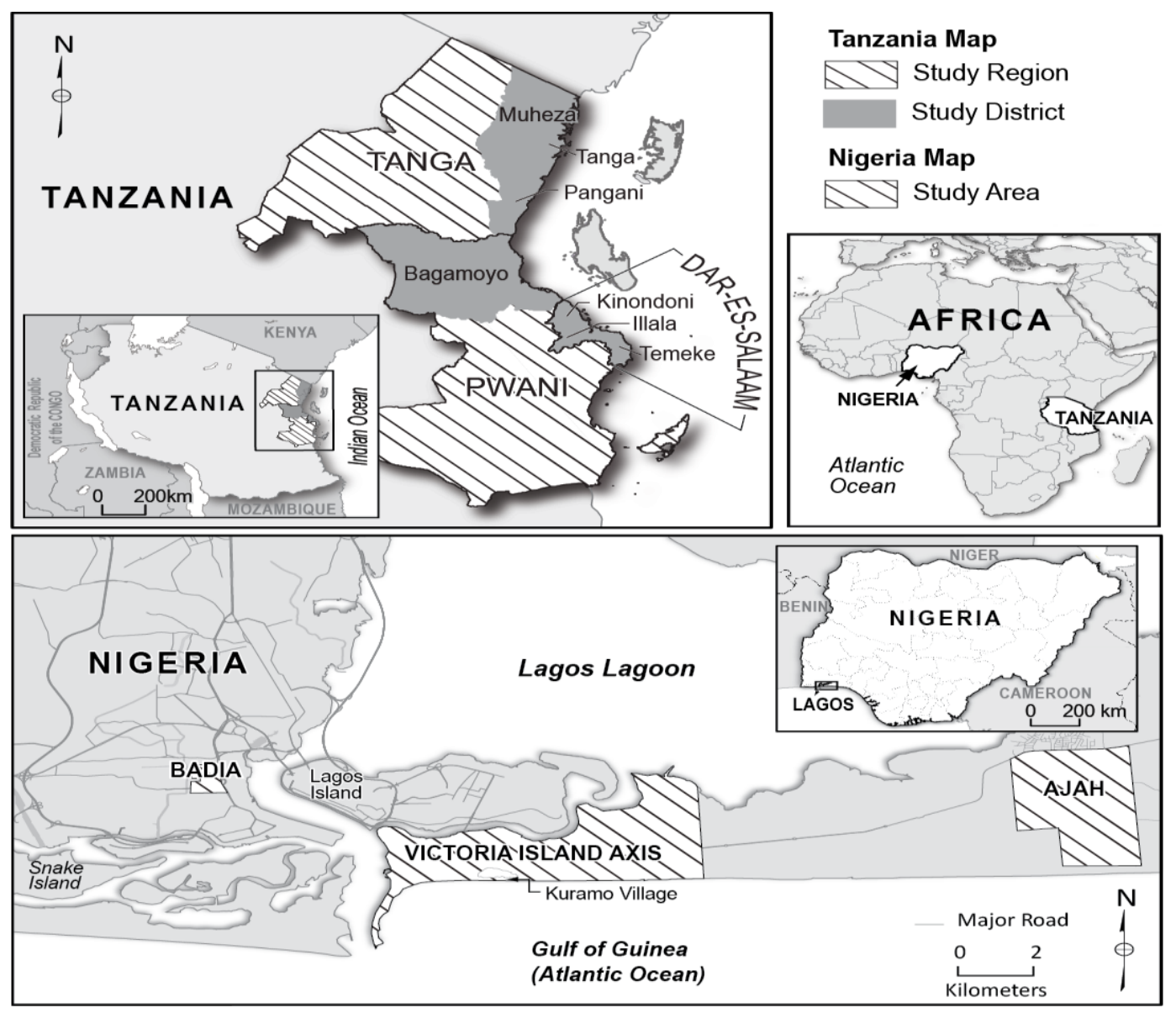

Figure 2. Map of Nigeria and Tanzania showing the study areas.

In Lagos, Nigeria, the study area comprises of three coastal communities namely Badia, Ajah and Victoria Island, which are predominantly urban. According to [13], Badia is a slum settlement in mainland Lagos with predominantly low-income people. The area is considered to be outside the city's formal development zone. Ajah is situated on the northern half of Lagos Island and home to a high proportion of middle- and upper-income people. This area was originally occupied by the indigenous community of Eti-Osa. Victoria Island, with its annex in Lekki Peninsula, is situated on the south of Lagos Island; and the area has both a high proportion of high-income households, and a smaller group of low-income people living in squatter settlements and neighbourhoods (Kuramo Beach settlement and Lekki-Jakande area).

In Tanzania, three contiguous regions (Dar es Salaam, Pwani and Tanga) in the northern Agroecological zone were selected. Dar es Salaam is the most urbanized region in Tanzania, whereas Pwani and Tanga regions are mostly rural. Dar es Salaam is the capital of the Dar es Salaam Region, which is one of Tanzania's 26 administrative regions. The Dar es Salaam Region consists of three local government areas or administrative districts: Kinondoni to the north, Ilala in the center of the region, and Temeke to the south. Pwani (coast) is the 21 st most densely populated region. It is bordered to the north by the Tanga Region, to the east by the Dar es Salaam Region and the Indian Ocean, to the south by the Lindi Region, and to the west by the Morogoro Region. Tanga region is bordered by Kenya and Kilimanjaro Region to the north; Manyara Region to the west; and Morogoro and Pwani regions to the south. Its eastern border is formed by the Indian Ocean. 


\subsection{Data Collection}

The study used multistage sampling to obtain representative estimates of the population of residents of the three areas in each country, and all men and women age 18 and older, who were permanent residents of the households, were eligible to be interviewed. In Lagos, Nigeria, the study was conducted in Ijora Badia, Ajah, and Victoria Island from August to September 2011. Based on the three communities, 7 neighbourhoods (Badia Central, Better Life, Abete, Ikoyi, Lekki, Ajah and Victoria Island) were randomly sampled with probability proportionate to size. Sample weights were then assigned to each resident to take into account variations in selection probabilities that occurred during various stages of sampling. A final sample of 1003 respondents consisting of 453 female and 550 male participants were interviewed in Nigeria. In Tanzania, the survey was conducted in three areas, namely Dar es Salaam, Pwani and Tanga, between March and September 2013. A total of 1253 residents comprising of 606 male and 647 female were sampled. The detail data collection techniques (description of the setting, locations, and relevant dates, including periods of recruitment, the eligibility criteria, and the sources and methods of selection of participants) used in Nigeria and Tanzania has been explained in [13] and [34], respectively. Tests of content validity, reliability and internal consistency of the survey instruments and measures have previously been explained by [35].

\subsection{Measures}

\subsubsection{Outcome Variable}

Adoption of coping strategies was measured as a dichotomized variable based on whether participants adopted any coping strategies after the most recent natural disaster they experienced or not (coded as, $0=$ did not adopt and $1=$ adopted). In Nigeria, $87 \%$ of participants indicated they adopted coping strategies, that is higher categories are more probable, therefore a complementary log-log link function was used to model the outcome variable. In Tanzania, only $36 \%$ of participants answered in the affirmative on adoption of coping strategies; hence lower categories are more probable. For this reason, a negative log-log link function was used to model the outcome variable. Throughout this paper, unless otherwise stated, adoption of coping strategies explicitly refers to reactive coping (post-disaster behaviour) rather than anticipatory coping (pre-disaster planning).

\subsubsection{Independent Variables}

The inclusion of key independent variables in the model was based on theoretical relevance, practical significance and potential confounding. Following previous studies [36], the variables were categorized into four main groups: stressful life experiences, personality disposition, social network resources and socio-demographic factors. Stressful life experiences consist of two dichotomous variables, experience of floods in the past one year and experience of ocean surges in the past one year. Personality disposition reveals self-efficacy and was operationalized in this study by self-rated health (poor $=1$, good $=2$, excellent $=3$ ). Social network resource was expressed by a dichotomous variable, access to family support during natural disaster $($ no $=0$, yes $=1$ ). Socio-demographic factors that have previously been shown to 
influence adoption of coping strategies were also accounted for in this study. These include age, location, educational attainment, employment status, housing quality and household income.

\subsection{Statistical Analysis}

The generalized linear model (GLM) simplifies linear regression by allowing the linear model to be related to the response variable via a link function and by allowing the magnitude of the variance of each measurement to be a function of its predicted value [37]. Under the assumption of binary response (i.e., did not adopt or adopted), there are several potential alternatives: the logit model, probit model, negative log-log and complementary log-log models, depending on the link function of the generalized linear model (GLM) [37,38]. Both logit and probit link functions have the same property, which is link $[\pi(x)=\log [-\log (1-\pi(x))]$. In this equation, the notation $\pi$ is the probability that an observation is in a specified category of the binary outcome variable (i.e., adoption of coping strategies or not), generally called the "success probability". The response curve for $\pi(\mathrm{x})$ has a symmetric appearance about the point $\pi(\mathrm{x})=0.5$ and so $\pi(\mathrm{x})$ has the same rate for approaching 0 as well as for approaching $1[37,38]$. In such an instance, it implies approximately $50 \%$ of participants adopted coping strategies or not. In this study, the outcome variable did not satisfy this symmetric distribution. When the number of respondents who adopted or did not adopt coping strategies are asymmetric in the $[0,1]$ interval, as is the case in this study, either a negative log-log or complementary log-log link function is appropriate for modeling the outcome variable [37,38].

The influence of stressful life experiences, personality disposition, social network resources, and socio-demographic factors on the likelihood of adoption of coping strategies were analyzed using odds ratios (ORs), established by binary complementary log-log regression (a generalized linear model) adjusted for the remaining independent variables included in the regression models for Nigeria. In Tanzania, the relationship between stressful life experiences, personality disposition, social network resources, and socio-demographic factors and the likelihood of adoption of coping strategies was established by log-log regression. $\mathrm{OR}=1$ implies that higher values of the predictor does not affect odds of adoption of coping strategies by participants; OR $>1$ implies that higher values of the predictor is associated with higher odds of adoption of coping strategies by participants, and $\mathrm{OR}<1$ implies that higher values of the predictor is associated with lower odds of adoption of coping strategies by participants. The generalized linear models in this study are built under the assumption of independence of subjects, but the cross-sectional survey has a hierarchical structure with respondents nested within survey clusters, which could potentially bias the standard errors. STATA 13 (StataCorp, College Station, TX, USA) SE, which has the capacity to address this problem, is used by imposing on our models a "cluster" variable, that is, the identification numbers of respondents at the cluster level. This, in turn, adjusts the standard errors (SE) producing statistically robust parameter estimates.

\section{Results}

\subsection{Descriptive Statistics of Outcome and Explanatory Variables in Nigeria and Tanzania}

The summary of the respondents' characteristics in Nigeria and Tanzania are shown in Table 1. Males and females are almost evenly distributed in both countries. In addition, the distribution 
of access to family support during floods was comparable in both countries. In Nigeria, three-fifth of respondents resided in Ijora Badia and more than four-fifth of respondents had experienced floods in the past year. Almost the same proportion of respondents however, had not experienced ocean surges in the past one year. About $60 \%$ of respondents were between 31 and 40 years old. Similarly, approximately $65 \%$ of participants had attained secondary or higher education.

Table 1. Sample characteristics of respondents in coastal communities in Nigeria and Tanzania.

\begin{tabular}{|c|c|c|c|c|}
\hline \multirow{2}{*}{ Adoption of Coping Strategies } & \multicolumn{2}{|c|}{ Nigeria $(N=1003)$} & \multicolumn{2}{|c|}{ Tanzania $(\mathrm{N}=1253)$} \\
\hline & Frequency & $\%$ & Frequency & $\%$ \\
\hline \multicolumn{5}{|l|}{ Stressful Life Experiences } \\
\hline \multicolumn{5}{|l|}{ Experience of floods in the past one year } \\
\hline No & 126 & 12.6 & 374 & 29.9 \\
\hline Yes & 877 & 87.4 & 879 & 70.1 \\
\hline \multicolumn{5}{|c|}{ Experience of ocean surges in the past one year } \\
\hline No & 804 & 80.2 & 568 & 45.3 \\
\hline Yes & 199 & 19.8 & 685 & 54.7 \\
\hline \multicolumn{5}{|l|}{ Personality Dispositions } \\
\hline \multicolumn{5}{|l|}{ Self-rated Health } \\
\hline Poor & 57 & 5.7 & 191 & 15.2 \\
\hline Good & 817 & 81.5 & 858 & 68.5 \\
\hline Excellent & 129 & 12.8 & 204 & 16.3 \\
\hline \multicolumn{5}{|l|}{ Social Network Resources } \\
\hline \multicolumn{5}{|l|}{ Family Support during floods } \\
\hline No & 896 & 89.3 & 1087 & 86.7 \\
\hline Yes & 107 & 10.7 & 166 & 13.3 \\
\hline \multicolumn{5}{|l|}{ Socio-Demographic Factors } \\
\hline \multicolumn{5}{|l|}{ Age } \\
\hline $18-25$ & 31 & 3.1 & 98 & 7.8 \\
\hline $26-30$ & 178 & 17.8 & 160 & 12.8 \\
\hline $31-35$ & 393 & 39.2 & 185 & 14.8 \\
\hline $36-40$ & 229 & 22.8 & 158 & 12.6 \\
\hline $41-45$ & 69 & 6.9 & 146 & 11.7 \\
\hline $46-50$ & 56 & 5.6 & 116 & 9.3 \\
\hline $51-$ & 47 & 4.7 & 390 & 31.1 \\
\hline \multicolumn{5}{|l|}{ Location (Nigeria/Tanzania) } \\
\hline Ijora Badia/Dar es Salaam & 607 & 60.5 & 601 & 48.0 \\
\hline Ajah/Pwani & 120 & 12.0 & 301 & 24.0 \\
\hline Victoria Island/Tanga & 276 & 27.5 & 351 & 28.0 \\
\hline \multicolumn{5}{|l|}{ Gender } \\
\hline Female & 453 & 45.2 & 647 & 51.6 \\
\hline Male & 550 & 54.8 & 606 & 48.4 \\
\hline \multicolumn{5}{|l|}{ Education (Ref: No education) } \\
\hline No Education & 16 & 1.6 & 107 & 8.5 \\
\hline Primary & 332 & 33.1 & 581 & 46.4 \\
\hline Secondary & 388 & 38.7 & 343 & 27.4 \\
\hline Tertiary & 267 & 26.6 & 222 & 17.7 \\
\hline
\end{tabular}


Table 1. Cont.

\begin{tabular}{|c|c|c|c|c|}
\hline \multirow{2}{*}{ Adoption of Coping Strategies } & \multicolumn{2}{|c|}{ Nigeria $(N=1003)$} & \multicolumn{2}{|c|}{ Tanzania $(N=1253)$} \\
\hline & Frequency & $\%$ & Frequency & $\%$ \\
\hline \multicolumn{5}{|l|}{ Socio-Demographic Factors } \\
\hline \multicolumn{5}{|l|}{ Employment Status } \\
\hline Unemployed & 105 & 10.5 & 126 & 10.1 \\
\hline Civil servant & 163 & 16.3 & 569 & 45.4 \\
\hline Artisan & 189 & 18.8 & 336 & 26.8 \\
\hline Self-employed & 546 & 54.4 & 222 & 17.7 \\
\hline \multicolumn{5}{|l|}{ Ethnicity (Nigeria / Tanzania) } \\
\hline Yoruba/Zaramo & 628 & 62.6 & 245 & 19.6 \\
\hline Ibo/Sambaa & 325 & 32.4 & 131 & 10.5 \\
\hline Hausa/Others & 50 & 5.0 & 877 & 70.0 \\
\hline \multicolumn{5}{|l|}{ Housing Quality } \\
\hline Poor & 493 & 49.2 & 1009 & 80.5 \\
\hline Good & 510 & 50.8 & 244 & 19.5 \\
\hline \multicolumn{5}{|l|}{ Income Groups (USD Equivalent) * } \\
\hline Up to 95.0 & 186 & 18.5 & 439 & 35.0 \\
\hline $95.1-160.0$ & 232 & 23.1 & 275 & 22.0 \\
\hline $160.1-325.0$ & 207 & 20.6 & 300 & 23.9 \\
\hline $325.1-400.0$ & 78 & 7.8 & 170 & 13.6 \\
\hline Greater than 400.0 & 300 & 29.9 & 69 & 5.5 \\
\hline
\end{tabular}

Notes: $R e f=$ reference category; * Income in Nigeria and Tanzania were originally measured in Naira and Shillings, respectively. Income quintiles are equivalent in both countries. Categories of location and ethnicity in Nigeria and Tanzania are reported beside each other.

In Tanzania, the number of respondents who had experienced floods in the past one year or not was not evenly distributed. A large proportion of respondents (70\%) had experienced floods in the past one year. Less than half of respondents had attained secondary or higher education. There were marked differences in the sorts of coping strategies respondents adopted across the two countries. For instance, In Nigeria, $87 \%$ of participants indicated that, in order to cope with floods, they said their prayers, waited out, temporarily relocated, cleared drainage channels, sand-filling, drained water from home with buckets, constructed wooden bridges, and dug small gutters. In Tanzania, however, 36\% of respondents claimed to have adopted coping strategies such as assuming a laissez faire attitude, permanently relocating, sand-filling, draining water from home, reliance on family or friends, reliance on social network, reliance on government.

The zero-order relationships between adoption of coping strategies by respondents and stressful life experiences in Nigeria and Tanzania (not reported) indicates explicit differences in terms of the magnitudes of the odds ratios and the levels of statistical significance of the predictors of adoption of coping strategies across the two countries. For instance, as a measure of effect size, the odds ratio of experience of floods in the past one year was four times higher in Nigeria than in Tanzania. Similarly, the odds ratio of social network resources in Tanzania was about three times higher than in Nigeria. Experience of ocean surges in the past one year was not a significant predictor of adoption of coping strategies in either of the two countries. In Nigeria, apart from experience of floods in the past one year, 
personal disposition, social network resources, age, location, education, employment status, ethnicity, housing quality and income levels were all significant predictors of adoption of coping strategies by respondents. The bivariate results in Nigeria sharply contrast with the results in Tanzania where only social network, age, employment status and income were significant predictors of adoption of coping strategies.

\subsection{Multivariate Relationships between Adoption of Coping Strategies and Predictors}

The results of the multivariate analyses across the two countries were quite interesting. An OR $=1$ suggests that higher values of the predictor does not influence likelihood of adoption of coping strategies by participants; an OR > 1 implies that higher values of the predictor is associated with higher likelihood of adoption of coping strategies by participants, and an $\mathrm{OR}<1$ implies that higher values of the predictor is associated with lower odds of adoption of coping strategies by participants. Statistical significance was set to $\alpha$ level of 0.05 .

In Nigeria, participants who experienced floods in the past one year were significantly far more likely to adopt coping strategies $(\mathrm{OR}=16.98, p<0.0001)$ than their counterparts who did not experience any floods (see Table 2). Likewise, those who experienced ocean surges in the past one year were more likely to adopt coping strategies than those who did not encounter any ocean surges although the magnitude of the odds ratios was lower $(\mathrm{OR}=2.48, p<0.0001)$. In terms of personality dispositions, individuals who reported excellent health $(\mathrm{OR}=2.48, p<0.01)$ and good health $(\mathrm{OR}=1.73, p<0.0001)$ were both more likely to adopt coping strategies compared to those who reported poor health. Individuals in the 26-30 age group were more likely ( $\mathrm{OR}=2.71, p<0.01$ ) to report adoption of coping strategies compared to those in the 18-25 age group. However, residents in Victoria Island were 67\% less likely to report adoption of coping strategies compared to their counterparts who reside in Ijora Badia. Respondents who had attained primary $(\mathrm{OR}=5.86, p \leq 0.001)$, secondary $(\mathrm{OR}=3.06, p<0.05)$ or tertiary education $(\mathrm{OR}=3.53$, $p<0.05)$ were all more likely to report adoption of coping strategies compared to their counterparts without any formal education. Interestingly, artisans and self-employed individuals were $65 \%$ and $60 \%$, respectively, less likely to report adoption of coping strategies compared to those who were unemployed. Hausas were significantly less likely $(\mathrm{OR}=0.30, p<0.05)$ to report adoption of coping strategies compared to individuals belonging to the Yoruba ethnic group. Quite expectedly, respondents who reported poor housing quality were $97 \%$ more likely to report adoption of coping strategies compared to individuals who reported good housing quality. Individuals in higher incomes were generally more likely to report adoption of coping strategies compared to individuals in the lowest income group. However, individuals in the highest income group were $74 \%$ less likely to report adoption of coping strategies compared to individuals in the lowest income group.

Table 2. Complementary log-log model showing the multivariate relationship between adoption of coping strategies and stressful life experiences in Lagos, Nigeria $(n=1003)$.

\begin{tabular}{|c|c|c|c|c|c|}
\hline Adoption of Coping Strategies & OR & Robust SE & $p$-Value & \multicolumn{2}{|c|}{$95 \% \mathrm{CI}$} \\
\hline \multicolumn{6}{|l|}{ Stressful Life Experiences } \\
\hline \multicolumn{6}{|c|}{ Experience of floods in the past one year (Ref: No) } \\
\hline Yes & 16.98 & 7.29 & 0.000 & 7.32 & 39.39 \\
\hline \multicolumn{6}{|c|}{ Experience of ocean surges in the past one year (Ref: No) } \\
\hline Yes & 2.48 & 0.64 & 0.000 & 1.50 & 4.11 \\
\hline
\end{tabular}


Table 2. Cont.

\begin{tabular}{|c|c|c|c|c|c|}
\hline Adoption of Coping Strategies & OR & Robust SE & $p$-Value & \multicolumn{2}{|c|}{$95 \% \mathrm{CI}$} \\
\hline \multicolumn{6}{|l|}{ Personality Dispositions } \\
\hline \multicolumn{6}{|l|}{ Self-rated Health (Ref: Poor) } \\
\hline Good & 1.73 & 0.41 & 0.020 & 1.09 & 2.74 \\
\hline Excellent & 2.48 & 0.74 & 0.003 & 1.38 & 4.46 \\
\hline \multicolumn{6}{|l|}{ Social Network Resources } \\
\hline \multicolumn{6}{|l|}{ Family Support during floods(Ref: None) } \\
\hline Yes & 1.64 & 0.49 & 0.095 & 0.92 & 2.93 \\
\hline \multicolumn{6}{|l|}{ Socio-Demographic Factors } \\
\hline \multicolumn{6}{|l|}{ Age (Ref:18-25) } \\
\hline $26-30$ & 2.71 & 0.90 & 0.003 & 1.41 & 5.20 \\
\hline $31-35$ & 1.20 & 0.36 & 0.539 & 0.67 & 2.16 \\
\hline $36-40$ & 0.84 & 0.25 & 0.556 & 0.46 & 1.52 \\
\hline $41-45$ & 0.54 & 0.19 & 0.086 & 0.26 & 1.09 \\
\hline $46-50$ & 2.43 & 1.32 & 0.102 & 0.84 & 7.04 \\
\hline $51-$ & 1.97 & 0.75 & 0.077 & 0.93 & 4.17 \\
\hline \multicolumn{6}{|l|}{ Location (Ref: Ijora Badia) } \\
\hline Ajah & 0.80 & 0.27 & 0.507 & 0.41 & 1.55 \\
\hline Victoria Island & 0.33 & 0.07 & 0.000 & 0.21 & 0.50 \\
\hline \multicolumn{6}{|l|}{ Gender (Reference: Female) } \\
\hline Male & 1.05 & 0.15 & 0.730 & 0.79 & 1.39 \\
\hline \multicolumn{6}{|l|}{ Education (Ref: No education) } \\
\hline Primary & 5.86 & 3.21 & 0.001 & 2.00 & 17.14 \\
\hline Secondary & 3.06 & 1.61 & 0.034 & 1.09 & 8.58 \\
\hline Tertiary & 3.53 & 1.99 & 0.025 & 1.17 & 10.65 \\
\hline \multicolumn{6}{|l|}{ Employment Status (Ref: Unemployment) } \\
\hline Civil servant & 0.69 & 0.22 & 0.236 & 0.37 & 1.28 \\
\hline Artisan & 0.35 & 0.10 & 0.000 & 0.20 & 0.63 \\
\hline self-employed & 0.40 & 0.10 & 0.000 & 0.24 & 0.66 \\
\hline \multicolumn{6}{|l|}{ Ethnicity (Ref: Yoruba) } \\
\hline Ibo & 0.88 & 0.14 & 0.426 & 0.65 & 1.20 \\
\hline Hausa & 0.30 & 0.12 & 0.004 & 0.13 & 0.67 \\
\hline \multicolumn{6}{|l|}{ Housing Quality (Ref: Good) } \\
\hline Poor & 1.97 & 0.30 & 0.000 & 1.46 & 2.65 \\
\hline \multicolumn{6}{|l|}{ Income Groups (Ref: up to 95 USD) * } \\
\hline $95.1-160.0$ & 3.16 & 0.72 & 0.000 & 2.02 & 4.95 \\
\hline $160.1-325.0$ & 2.39 & 0.51 & 0.000 & 1.57 & 3.64 \\
\hline $325.1-400.0$ & 1.88 & 0.58 & 0.039 & 1.03 & 3.43 \\
\hline Greater than 400.0 & 0.26 & 0.17 & 0.045 & 0.07 & 0.97 \\
\hline
\end{tabular}

Note: $R e f=$ reference category; * Income in Nigeria and Tanzania were originally measured in Naira and Shillings, respectively.

In Tanzania, the zero-order relationships between age, employment and income on the one hand and adoption of coping strategies on the other hand, were not statistically robust and therefore disappeared at the multivariate level (see Table 3). Only experience of floods in the past one year and social network 
resources were significant predictors of adoption of coping strategies by participants unlike in Nigeria where a plethora of factors were still statistically significant at the multivariate level. These include experience of ocean surges in the past one year, experience of flood in the past one year, personality disposition, age, education, ethnicity, income, housing quality and employment status (Table 3).

Table 3. Negative log-log model showing multivariate relationship between adoption of coping strategies and stressful life experiences in coastal communities in Tanzania $(\mathrm{n}=1253)$.

\begin{tabular}{|c|c|c|c|c|c|}
\hline Adoption of Coping Strategies & OR & Robust SE & $p$-Value & \multicolumn{2}{|c|}{$95 \% \mathrm{CI}$} \\
\hline \multicolumn{6}{|l|}{ Stressful Life Experiences } \\
\hline \multicolumn{6}{|l|}{ Experience of floods in the past one year (Ref: No) } \\
\hline Yes & 2.96 & 0.28 & 0.000 & 2.46 & 3.57 \\
\hline \multicolumn{6}{|l|}{ Experience of ocean surges in the past one year (Ref: } \\
\hline \multicolumn{6}{|l|}{ No) } \\
\hline Yes & 1.12 & 0.10 & 0.192 & 0.94 & 1.34 \\
\hline \multicolumn{6}{|l|}{ Personality Dispositions } \\
\hline \multicolumn{6}{|l|}{ Self-rated Health (Ref: Poor) } \\
\hline Good & 1.19 & 0.14 & 0.159 & 0.94 & 1.50 \\
\hline Excellent & 1.19 & 0.19 & 0.286 & 0.87 & 1.62 \\
\hline \multicolumn{6}{|l|}{ Social Network Resources } \\
\hline Family Support during floods(Ref: None) & 1.76 & 0.24 & 0.000 & 1.34 & 2.31 \\
\hline \multicolumn{6}{|l|}{ Yes } \\
\hline \multicolumn{6}{|l|}{ Socio-Demographic Factors } \\
\hline \multicolumn{6}{|l|}{ Age (Ref:18-25) } \\
\hline $26-30$ & 0.95 & 0.18 & 0.763 & 0.66 & 1.36 \\
\hline $31-35$ & 0.80 & 0.15 & 0.224 & 0.56 & 1.15 \\
\hline $36-40$ & 1.00 & 0.19 & 0.989 & 0.70 & 1.44 \\
\hline $41-45$ & 0.93 & 0.18 & 0.699 & 0.63 & 1.36 \\
\hline $46-50$ & 0.81 & 0.16 & 0.287 & 0.55 & 1.19 \\
\hline $51-$ & 0.98 & 0.17 & 0.921 & 0.70 & 1.39 \\
\hline \multicolumn{6}{|l|}{ Location (Ref: Dar es Salaam) } \\
\hline Pwani & 1.09 & 0.13 & 0.480 & 0.86 & 1.39 \\
\hline Tanga & 1.18 & 0.13 & 0.143 & 0.95 & 1.47 \\
\hline \multicolumn{6}{|l|}{ Gender (Ref: Male) } \\
\hline Female & 1.16 & 0.10 & 0.086 & 0.98 & 1.37 \\
\hline \multicolumn{6}{|l|}{ Education (Ref: No education) } \\
\hline Primary & 1.19 & 0.19 & 0.276 & 0.87 & 1.61 \\
\hline Secondary & 1.01 & 0.18 & 0.969 & 0.70 & 1.44 \\
\hline Tertiary & 0.96 & 0.22 & 0.854 & 0.60 & 1.52 \\
\hline \multicolumn{6}{|l|}{ Employment Status (Ref: Unemployment) } \\
\hline Civil servant & 1.24 & 0.19 & 0.142 & 0.93 & 1.67 \\
\hline Artisan & 1.09 & 0.17 & 0.574 & 0.80 & 1.48 \\
\hline self-employed & 0.81 & 0.13 & 0.201 & 0.59 & 1.12 \\
\hline
\end{tabular}


Table 3. Cont.

\begin{tabular}{|c|c|c|c|c|c|}
\hline Adoption of Coping Strategies & OR & Robust SE & p-value & \multicolumn{2}{|c|}{$95 \% \mathrm{CI}$} \\
\hline \multicolumn{6}{|l|}{ Socio-Demographic Factors } \\
\hline \multicolumn{6}{|l|}{ Ethnicity (Ref: Zaramo) } \\
\hline Sambaa & 0.95 & 0.16 & 0.781 & 0.68 & 1.33 \\
\hline Others & 0.93 & 0.12 & 0.577 & 0.73 & 1.19 \\
\hline \multicolumn{6}{|l|}{ Housing Quality (Ref: Good) } \\
\hline Poor & 1.04 & 0.12 & 0.758 & 0.83 & 1.29 \\
\hline \multicolumn{6}{|l|}{ Income Groups (Ref: up to 95 USD) * } \\
\hline $95.1-160.0$ & 1.18 & 0.13 & 0.137 & 0.95 & 1.47 \\
\hline $160.1-325.0$ & 1.21 & 0.16 & 0.157 & 0.93 & 1.56 \\
\hline $325.1-400.0$ & 1.11 & 0.21 & 0.585 & 0.76 & 1.62 \\
\hline Greater than 400.0 & 0.85 & 0.22 & 0.538 & 0.51 & 1.43 \\
\hline
\end{tabular}

Note: $R e f=$ reference category; * Income in Nigeria and Tanzania were originally measured in Naira and Shillings, respectively.

In Tanzania, individuals who had experienced floods in the past one year were more likely to adopt coping strategies $(\mathrm{OR}=2.96, p \leq 0.05)$ compared to their counterparts who did not experience floods in the past one year. Similarly, respondents who had access to family support during floods were $76 \%$ more likely to adopt coping strategies compared to those without access to family support during floods.

\section{Discussion}

This paper examined the relationship between stressful life experiences and the adoption of coping strategies among coastal dwellers in Tanzania and Nigeria. The stressful life experiences used in this study were the experience of floods and ocean surges within the past one year. Relationships between stressful life events and the adoption of relevant coping strategies have been explored in several studies [39-43]. In this study, our overall findings show that individuals in both Tanzania and Nigeria who experienced stressful life events engaged in the adoption of coping strategies. However, it is important to indicate that certain distinctions where observed across the two countries. Experience of both floods and ocean surges were important predictors in Nigeria unlike in Tanzania where only experience of flood was an important predictor of the adoption of coping strategies. We argue that residents of islands (i.e., Victoria Island) were more predisposed to experiencing ocean surges.

In the case of Tanzania, only social networks emerged as a significant predictor of the adoption of coping strategies after controlling for theoretically relevant factors. This finding corroborates existing literature, which indicates the importance of social networks in disaster recovery efforts [44-46]. Such networks provide the necessary social capital required for recovering after disasters have occurred. For example, Fletcher et al. [47] found that among Pacific island dwellers, kinship ties are not just critical support structures during disasters but are also important for coordination of disaster response and are critical in developing suitable coping skills. It is noteworthy that the significance of social network in the adoption of coping strategies was observed in Tanzania and not in Nigeria. This observed difference might be due to varying levels of rural-urban distribution of the study populations in the two countries. Whilst the coastal communities in Nigeria included in this study were mainly urban, the study communities in Tanzania included rural areas. Rural areas generally tend to still retain strong kinship 
ties which act as critical support systems in times of disaster - a phenomenon which has generally eroded in urban areas [47].

Personality disposition (self-rated health status), age, location, educational level, occupation, ethnicity, housing quality and income were all significant predictors of the adoption of coping strategies in Nigeria unlike in Tanzania. In our study, good and excellent self-reported health status was associated with the adoption of coping strategies. Health status has been identified as a basic capability, which forms part of the tools required to anticipate and effectively respond to specific climatic threats [48]. This suggests that individuals in these groups have the capacity to actively respond to threats from extreme climate events. Individuals between 26 and 30 years old had higher odds of adopting coping strategies compared to their counterparts who were 25 years old or younger. Some studies have found that age is a significant predictor of coping strategy adopted after the experience of flood $[49,50]$. In addition, Hisali et al. [51] found that in Uganda, age of household heads reduced the odds of adapting coping strategies to mitigate their vulnerability to extreme climate events.

Consistent with other studies [52-54], we found that location was a determinant of the adoption of coping strategies in Nigeria. Our findings indicate that residents of Victoria Island were less likely to adopt coping strategies. This finding is not surprising because Victoria Island is categorised as a high-income location and is generally well planned and possess adequate infrastructure unlike most informal settlements in developing countries. Informal settlements tend to be situated in environmentally precarious locations where they are susceptible to frequent environmental disasters [12] and their residents engage in the adoption of coping strategies to help mitigate the impact of disasters [55]. The well-planned infrastructure in Victoria Island signifies anticipatory rather than reactive coping.

Educational level and occupation tend to be closely related. It was therefore not surprising that we found significant association between adoption of coping strategies and these two factors. Individuals who had attained primary, secondary or tertiary education had higher odds of adopting coping strategies compared to uneducated counterparts. Importantly, research suggests that differences in educational levels and occupations results in differences in the perception of weather conditions and related disasters $[49,54,56]$ and by extension, the decision to adopt coping strategies. Such difference may be the result of knowledge and experience obtained through the practice of occupations with direct links to weather events or through information obtained via education.

The significance of the relationship between adoption of coping strategies and housing quality is intuitive because individuals who live in lower quality dwellings are likely to be severely impacted by floods and ocean surges leading to the adoption of coping strategies. Evidence shows that individuals residing in low quality housing tend to be negatively impacted by disasters, necessitating the adoption of coping strategies [23].

Socio-economic status as an important factor in predicting adoption of coping strategies has received extensive scholarly attention. In Nigeria, individuals in lower income categories adopt coping strategies. This finding is inconsistent with what [56] found in Bangladesh. We suggest that the inconsistency in findings is because higher income status in Nigeria probably confers on individuals the ability to acquire property in locations, which are less susceptible to the floods and ocean surges. Consequently, the extent of damage by floods and ocean surges in the aftermath of disaster may not warrant the adoption of coping strategies.

This study is not without limitations. Data used in this study are cross-sectional in nature and only capture the non-causal relationship between adoption of coping strategies and previous experience of 
stressful life events. Specifically, the study relied on respondents' self-reported experience of extreme climate events in the last one-year. Self-reporting can be inaccurate due be recall bias, social desirability bias and errors in self-observation. However, steps were taken to address some of these issues, for instance, to reduce recall bias we limited the dependent variable to only one year. Besides, self-reporting is the most simple and inexpensive method of measuring adherence to coping strategies.

\section{Policy Implications}

By and large, a combination of geography, population density, and extreme poverty makes populations in both Nigeria and Tanzania vulnerable to flood risks. Analysis of the relationship between flood incidence and adoption of coping strategies in both countries suggests a multi-pronged approach to flood risk management and coping capacity enhancement is required. Attention needs to be given to reducing the sensitivity to floods of poor households by improving economic and social wellbeing [57] in the two countries. This attention to reducing sensitivities, as well improving people's ability to respond to and cope with flood events, applies equally when developing and implementing efforts to encourage both economic development and flood risk management $[7,58]$.

The results of this study bring to the fore two interesting issues. First, higher income households (e.g., in Victoria Island in Lagos) often live in high risk areas because of the aesthetic attributes of living next to water, and their ability to afford the premium from flood insurance. Second, low-income households (e.g., in Ijora Badia in Lagos) live in higher risk areas than middle-income households in order to find affordable housing. Consequently, the poor are more exposed to flood hazards than those from middle-income households. This is a public policy issue for the reason that the poor are less likely to recover from economic losses emanating from floods induced by anthropogenic climate change. From this study, it is evident that individuals in the poorest quintile are disproportionately impacted by climate change-induced increases in flood risk especially in urban localities. In this instance, there may be more flood exposure bias, at sub-national scales warranting the need for policy priority. It is, therefore, imperative to pinpoint areas where high poverty and flood exposure coincide. Since approximately nineteen percent and thirty-five percent of respondents, respectively, in Nigeria and Tanzania are already in the poorest quintile, heightened vulnerability to floods is a major social challenge for both countries. In Dar es Salaam, for example, integration of flood risk management approaches in urban planning is rather inadequate and climate change is likely to exacerbate vulnerability over coming decades. For such respondents in this city, uncertainty over when floods will occur is a serious problem for short-term risk management.

Perhaps, one of the most controversial issues in the burgeoning literature on hydro-meteorological events is whether certain ethnic groups are exposed to larger hazards. We found that in Lagos, individuals belonging to the Hausa ethnic group were less likely to adopt coping strategies compared to their Yoruba counterparts. The findings of this study have several implications on flood policymaking across the two countries especially in the context of anthropogenic climate change. Until now, flood policies in both countries are either non-existent or not comprehensive. The flood policy environment in the face of increasing climate change-induced risks is evolving. That process has evolved from targeted policies and single-issue instruments in the last two decades, through diffuse policy integration and public awareness in the past 10 years, to policy coherence and other systemic approaches over the last five years. This is evidenced by the trans-boundary basin management and integrated coastal zone 
management initiatives on flood risk reduction adopted in both countries. Policy efforts to address flood impacts of climate change will require strengthening of legislative and institutional frameworks [7,58]. Although the contexts differ in both countries, some cross cutting issues of policy relevance are evident. For instance, both countries are characterized by poor and low implementation capacities as well as lack of financial resources. In the adoption of coping strategies, both countries must depart from short-term flood disaster responses, and target long-term adaptation measures and policies that will be implemented at national and local levels focusing on land-use planning (with increased resilience in informal settlements as primary focus), as well as building adaptive capacity and taking action to increase resilience to climate change.

\section{Conclusions}

In this paper, we assessed the relationship between likelihood of adoption of coping strategies and previous experience of stressful life events, personality disposition, social network resources and socio-demographic factors in Nigeria and Tanzania. Our findings demonstrate that influence of stressful life experience on adoption of coping strategies is spatially ubiquitous. This finding is significant within the context of increasing concerns about climate change, which exacerbates hydro-meteorological disasters. Regardless of this, our findings also show specific cross-country differentials in the predictors of adoption of flood-related coping strategies. This suggests that context-specific policies aimed at encouraging the adoption of coping strategies in vulnerable locations should be designed based on local needs and orientation.

\section{Acknowledgements}

We thank the Coastal Cities at Risk (CCaR) project, which is part of the International Research Initiative on Adaptation to Climate Change (IRIACC) for funding the research project in Nigeria. For the study in Tanzania, we acknowledge research funding from "the Indian Ocean World: The Making of the First Global Economy in the Context of Human Environment Interaction" project within the framework of Major Collaborative Research Initiative (MCRI). The funders had no role in study design, data collection and analysis, decision to publish, or preparation of the manuscript. Many thanks to Karen Van Kerkoerle, of the Cartographic Unit, Department of Geography, University of Western Ontario, Canada for drawing the map of the study areas.

\section{Author Contributions}

Frederick Ato Armah and Idowu Ajibade made substantial contributions to conception, design and acquisition of data for the studies in Tanzania and Nigeria, respectively. All authors were involved in analysis and interpretation of data. All authors made substantial contributions to drafting the article and revising it critically for important intellectual content. All authors were involved in final approval of the version to be published. They also agreed to be accountable for all aspects of the work in ensuring that questions related to the accuracy or integrity of any part of the work are appropriately investigated and resolved. 


\section{Conflicts of Interest}

The authors declare no conflict of interest.

\section{References}

1. Pachauri, R.K.; Gnacadja, L.; Afes-press, H.G.; Cutajar, M.Z.; Steiner, A.; Behera, N.C.; Krummenacher, H. Facing Global Environmental Change: Environmental, Human, Energy, Food, Health and Water Security Concepts; Springer: Berlin, Germany, 2009.

2. Balica, S.; Wright, N.; van der Meulen, F. A flood vulnerability index for coastal cities and its use in assessing climate change impacts. Nat. Hazards 2012, 64, 73-105.

3. Aerts, J.; Botzen, W.; Bowman, M.; Dircke, P.; Ward, P. Climate Adaptation and Flood Risk in Coastal Cities; Routledge: New York, NY, USA, 2013.

4. Few, R. Flood Hazards and Health: Responding to Present and Future Risks; Routledge: London, UK, 2013.

5. Ahern, M.; Kovats, R.; Wilkinson, P.; Few, R.; Matthies, F. Global health impacts of floods: Epidemiologic evidence. Epidemiol. Rev. 2005, 27, 36-46.

6. Few, R.; Ahern, M.; Matthies, F.; Kovats, S. Floods, Health and Climate Change: A Strategic Review; Tyndall Centre for Climate Change Research: Norwich, UK, 2004.

7. Ward, P.; Jongman, B.; Weiland, F.; Bouwman, A.; van Beek, R.; Bierkens, M.; Ligtvoet, W.; Winsemius, H. Assessing flood risk at the global scale: Model setup, results, and sensitivity. Environ. Res. Lett. 2013, 8, doi:10.1088/1748-9326/8/4/044019.

8. Doocy, S.; Daniels, A.; Murray, S.; Kirsch, T. The human impact of floods: A historical review of events 1980-2009 and systematic literature review. PLoS Curr. 2013, 5, doi:10.1371/currents.dis. 67bd14fe457f1db0b5433a8ee20fb833.

9. OFDA-CRED. The OFDA-CRED International Disaster Database 2002. Available online: Http:// www.em_dat.net/disasters/profiles.php (accessed on 11 November 2015).

10. Tapsell, S.M.; Tunstall, S.M. I wish I'd never heard of Banbury: The relationship between 'place' and the health impacts from flooding. Health Place 2008, 14, 133-154.

11. Mulugeta, G.; Ayonghe, S.; Daby, D.; Dube, O.; Gudyanga, F.; Lucio, F.; Durrheim, R. Natural and Human-Induced Hazards and Disasters in Sub-Saharan Africa, ICSU Regional Office for Africa. Available online: http://www.icsu.org/africa/publications/reports-and-reviews/icsu-roa-scienceplan-on-hazards-disasters/ (accessed on 16 January 2015).

12. Ajibade, I.; Armah, F.; Kuuire, V.; Luginaah, I.; McBean, G.; Tenkorang, E. Assessing the bio-psychosocial correlates of flood impacts in coastal areas of Lagos, Nigeria. J. Environ. Plan. Manag. 2015, 58, 445-463.

13. Ajibade, I.; Armah, F.; Kuuire, V.; Luginaah, I.; McBean, G. Self-reported experiences of climate change in Nigeria: The role of personal and socio-environmental factors. Climate 2015, 3, 16-41.

14. Cutter, S.L.; Emrich, C.T. Moral hazard, social catastrophe: The changing face of vulnerability along the hurricane coasts. Ann. Am. Acad. Pol. Soc. Sci. 2006, 604, 102-112.

15. Kithiia, J. Climate change risk responses in East African cities: Need, barriers and opportunities. Curr. Opin. Environ. Sustain. 2011, 3, 176-180. 
16. Brown, S.; Kebede, A.S.; Nicholls, R.J. Sea-Level Rise and Impacts in Africa, 2000 to 2100. Available online: http://www.unep.org/climatechange/adaptation/Portals/133/documents/Adapt Cost/9\%20Sea\%20Level\%20Rise\%20Report\%20Jan\%202010.pdf (accessed on 26 January 2015).

17. Kundzewicz, Z.; Kanae, S.; Seneviratne, S.; Handmer, J.; Nicholls, N.; Peduzzi, P.; Mechler, R.; Bouwer, L.; Arnell, N.; Mach, K.; et al. Flood risk and climate change: Global and regional perspectives. Hydrol. Sci. J. 2014, 59, 1-28.

18. Schiermeier, Q. Increased flood risk linked to global warming. Nature 2011, 470, 316-316.

19. Wilby, R.; Keenan, R. Adapting to flood risk under climate change. Prog. Phys. Geogr. 2012, 36, 348-378.

20. Douglas, I.; Alam, K.; Maghenda, M.; Mcdonnell, Y.; Mclean, L.; Campbell, J. Unjust waters: Climate change, flooding and the urban poor in Africa. Environ. Urban. 2008, 20, 187-205.

21. OCHA. 2013 Rainy Season Preview: West and Central Africa. Available online: http://reliefweb. int/sites/reliefweb.int/files/resources/Rains\%20Report\%202013\%20FINAL\%2011092013.pdf (accessed on 11 November 2015).

22. Satterthwaite, D. Adapting to Climate Change in Urban Areas: The Possibilities and Constraints in Low-And Middle-Income Nations; IIED: London, UK, 2007.

23. Ajibade, I.; McBean, G. Climate extremes and housing rights: A political ecology of impacts, early warning and adaptation constraints in Lagos slum communities. Geoforum 2014, 55, 76-86.

24. Nicholls, R.J.; Hanson, S.; Herweijer, C.; Patmore, N.; Hallegatte, S.; Corfee-Morlot, J.; Château, J.; Muir-Wood, R. Ranking Port Cities with High Exposure and Vulnerability to Climate Extremes: Exposure Estimates, 2008. Available online: http://dx.doi.org/10.1787/011766488208 (accessed on 11 November 2015).

25. UN Habitat. The State of African Cities 2014: Re-Imagining Sustainable Urban Transitions; United Nations Human Settlements Programme: Nairobi, Kenya, 2014.

26. Lazarus, R.; Folkman, S. Stress, Appraisal, and Coping; Springer: Berlin, Germany, 1984.

27. Lazarus, R. Stress and Emotion; Springer: Berlin, Germany, 1999.

28. Kahneman, D.; Fredrickson, B.; Schreiber, C.; Redelmeier, D. When more pain is preferred to less: Adding a better end. Science 1993, 4, 401-405.

29. Miron-Shatz, T.; Stone, A.; Kahneman, D. Memories of yesterday's emotions: Does the valence of experience affect the memory-experience gap? Emotion 2009, 9, 885-891.

30. Chun, C.A.; Moos, R.H.; Cronkite, R.C. Culture: A fundamental context for the stress and coping paradigm. In Handbook of Multicultural Perspectives on Stress and Coping; Springer: Berlin, Germany, 2006.

31. Perilla, J.; Norris, F.; Lavizzo, E. Ethnicity, culture, and disaster response: Identifying and explaining ethnic differences in PTSD six months after Hurricane Andrew. J. Soc. Clin. Psychol. 2002, 21, 20-45.

32. Folkman, S.; Lazarus, R. An analysis of coping in middle-aged community sample. J. Health Soc. Behav. 1980, 21, 219-239.

33. Aldwin, C.; Sutton, K.; Lachman, M. The development of coping resources in adulthood. J. Pers. 1996, 64, 837-871. 
34. Armah, F.; Luginaah, I.; Yengoh, G.; Hambati, H.; Chuenpagdee, R.; Campbell, G. Analyzing the relationship between objective-subjective health status and public perception of climate change as a human health risk in coastal Tanzania. Human Ecol. Risk Assess. 2015, 21, 1936-1959.

35. Armah, F.; Luginaah, I.; Hambati, H.; Chuenpagdee, R.; Campbell, G. Assessing barriers to adaptation to climate change in coastal Tanzania: Does where you live matter? Popul. Environ. 2015, 37, 231-263.

36. Holahan, C.J.; Moos, R.H. Personal and contextual determinants of coping strategies. J. Pers. Soc. Psychol. 1987, 52, doi:10.1037/0022-3514.52.5.946.

37. Aitkin, M.; Francis, B.; Hinde, J. Statistical Modelling in GLIM 4; Oxford University Press: Oxford, UK, 2005.

38. Fahrmeir, L.; Tutz, G. Multivariate Statistical Modelling Based on Generalised Linear Models; Springer: Berlin, Germany, 2001.

39. Mishra, S.; Suar, D. Effects of anxiety, disaster education, and resources on disaster preparedness behavior. J. Appl. Soc. Psychol. 2012, 42, 1069-1087.

40. Bubeck, P.; Botzen, W.; Suu, L.; Aerts, J. Do flood risk perceptions provide useful insights for flood risk management? Findings from central Vietnam. J. Flood Risk Manag. 2012, 5, 295-302.

41. Bubeck, P.; Botzen, W.; Kreibich, H.; Aerts, J. Detailed insights into the influence of flood-coping appraisals on mitigation behaviour. Glob. Environ. Chang. 2013, 23, 1327-1338.

42. Poussin, J.K.; Botzen, W.W.; Aerts, J.C. Factors of influence on flood damage mitigation behaviour by households. Environ. Sci. Policy 2014, 40, 69-77.

43. Boer, J.; Wouter Botzen, W.J.; Terpstra, T. More than fear induction: Toward an understanding of people's motivation to be well prepared for emergencies. In Risk Analysis; Wiley: New York, NY, USA, 2015.

44. Nakagawa, Y.; Shaw, R. Social capital: A missing link to disaster recovery. Int. J. Mass Emerg. Disasters 2004, 22, 15-34.

45. Aldrich, D. The power of people: Social capital's role in recovery from the 1995 Kobe earthquake. Nat. Hazards 2011, 56, 595-611.

46. Chamlee-Wright, E.; Storr, V. Social capital as collective narratives and post-disaster community recovery. Sociol. Rev. 2011, 59, 266-282.

47. Fletcher, S.; Thiessen, J.; Gero, A.; Rumsey, M.; Kuruppu, N.; Willetts, J. Traditional coping strategies and disaster response: Examples from the South Pacific region. J. Environ. Public Health 2013, 2013, 1-9.

48. Eakin, H.; Lemos, M.; Nelson, D. Differentiating capacities as a means to sustainable climate change adaptation. Glob. Environ. Chang. 2014, 27, 1-8.

49. Sultana, N.; Rayhan, M. Coping strategies with floods in Bangladesh: An empirical study. Nat. Hazards 2012, 64, 1209-1218.

50. Berman, R.; Quinn, C.; Paavola, J. Identifying drivers of household coping strategies to multiple climatic hazards in Western Uganda: Implications for adapting to future climate change. Clim. Dev. 2014, 7, 71-84.

51. Hisali, E.; Birungi, P.; Buyinza, F. Adaptation to climate change in Uganda: Evidence from micro level data. Glob. Environ. Chang. 2011, 21, 1245-1261. 
52. Bantilan, M.C.S.; Singh, N.P.; Byjesh, K.; Padmaja, R.; Jayatilaka, W. Vulnerability to Climate Change: Adaptation Strategies and Layers of Resilience. Available online: http://oar.icrisat.org/ 6549/1/Policy\%20Brief\%2023.pdf (accessed on 11 November 2015).

53. Gioli, G.; Khan, T.; Scheffran, J. Climatic and environmental change in the Karakoram: Making sense of community perceptions and adaptation strategies. Reg. Environ. Chang. 2014, 14, 1151-1162.

54. Mondal, T.K. People's Perception on natural disasters and local survival strategies in Sundarban Region: A study of Gosaba Block in South Twenty Four Parganas District in West Bengal, India. In Community, Environment and Disaster Risk Management; Emerald Group Publishing Limited: Dar es Salaam, Tanzania, 2014.

55. Sakijege, T.; Lupala, J.; Sheuya, S. Flooding, flood risks and coping strategies in urban informal residential areas: The case of Keko Machungwa, Dar es Salaam, Tanzania: Original research. J. Disaster Risk Stud. 2012, 4, 1-10.

56. Paul, S.; Routray, J. Household response to cyclone and induced surge in coastal Bangladesh: Coping strategies and explanatory variables. Nat. Hazards 2011, 57, 477-499.

57. Winsemius, H.; van Beek, L.; Jongman, B.; Ward, P.; Bouwman, A. A framework for global river flood risk assessments. Hydrol. Earth Syst. Sci. 2013, 17, 1871-1892.

58. Jongman, B.; Ward, P.; Aerts, J. Global exposure to river and coastal flooding: Long term trends and changes. Glob. Environ. Chang. 2012, 22, 823-835.

(C) 2015 by the authors; licensee MDPI, Basel, Switzerland. This article is an open access article distributed under the terms and conditions of the Creative Commons Attribution license (http://creativecommons.org/licenses/by/4.0/). 